\title{
Publicação continuada: algumas reflexões
}

\author{
Samile Andrea de Souza Vanz \\ Doutora; Universidade Federal do Rio Grande do Sul, Porto Alegre, RS, Brasil; \\ samile.vanz@ufrgs.br \\ Lúcia da Silveira \\ Doutoranda; Universidade Federal do Rio Grande do Sul, Porto Alegre, RS, Brasil \\ lucia.silveira@ufsc.br
}

A qualificação das revistas brasileiras envolve fatores que vão além da qualidade das pesquisas publicadas nos artigos per se. Perpassa a profissionalização das equipes editoriais, o cumprimento da periodicidade, o atendimento aos padrões nacionais e internacionais da própria comunicação científica, recebendo influências de agências de financiamento de pesquisa e indexadores (editoras comerciais ou públicas) de informação científica.

No Brasil, alguns atores desempenharam papel fundamental para a evolução da publicação periódica: o Instituto Brasileiro de Informação em Ciência e Tecnologia (IBICT), os Portais de Periódicos Institucionais e a SciELO.

O IBICT agiu estrategicamente a partir da tradução do Open Journal System (OJS) em 2003. O software da Public Knowledge Project (PKP) foi desenvolvido para criação e gerenciamento de revistas eletrônicas, proporcionando a automação nos processos editoriais. No cenário brasileiro, onde grande parte das revistas científicas são publicadas por instituições de pesquisa, associações ou universidades, o Sistema Eletrônico de Editoração de Revistas (SEER) foi distribuído gratuitamente, direcionando vários editores à adoção do SEER (VANZ; SILVA FILHO, 2019).

Por sua vez, os Portais de Periódicos Institucionais surgiram pouco depois dessa ação do IBICT e foram os agentes responsáveis por implementar o software de gestão editorial OJS nas universidades. Essa ação, integrada com outros fatores (como o acesso aberto), impulsionou os portais de periódicos, que quando bem consolidados auxiliam os editores a projetar, manter a qualidade do 
periódico, monitorar e implementar as tendências, entre outros (SILVEIRA; SPUDEIT, 2016).

Outro ator fundamental no cenário é a Scientific Electronic Library Online (SciELO), principal fonte de informação multidisciplinar brasileira reconhecida internacionalmente, que objetiva promover a produção científica de países latino americanos avançando para outros países como Portugal, África, Espanha, entre outros. A SciELO conquistou seu espaço por considerar padrões de publicação que seguiam o ritmo internacional.

Nesse sentido, a SciELO tem conduzido os rumos das revistas científicas brasileiras por meio da publicação de seus critérios para admissão na coleção. Estes critérios regulam a periodicidade das revistas, filiação dos autores, endogenia, ações de divulgação, modalidade de publicação, entre outros aspectos. Em 2014, a SciELO recomendava a adoção da publicação antecipada dos artigos, mas já sinalizava que a publicação contínua facilita o cumprimento da pontualidade (SciELO, 2014). Nos critérios publicados em 2017, a SciELO passou a indicar a preferência pelo formato de publicação contínua dos artigos, tão $\operatorname{logo}$ sejam aprovados e editados, com a posterior reunião em um volume anual com ou sem fascículos (SciELO, 2017).

A publicação contínua, também denominada publicação continuada, no inglês, continuous publication, rolling pass e rolling publishing, e em espanhol, publicación continua, é uma modalidade recente de publicação científica, que consiste em publicar o artigo individualmente e de forma definitiva, identificado por um número, normalmente sequencial, que o localiza no fascículo e volume. A organização dos artigos em fascículos é opcional, ou seja, o periódico pode editar somente o volume, que normalmente coincide com o ano calendário. A mudança mais importante em relação à publicação seriada tradicional é a forma de localização do artigo na coleção do periódico, que passa a ser feita por um número ao invés da página inicial e final (PACKER et al., 2016).

A redução do tempo decorrido entre a decisão editorial e a publicação dos artigos é, sem dúvida, fator que colabora para a qualificação das revistas. A modalidade de publicação continuada auxilia nesta tarefa. A disponibilização mais rápida dos resultados de pesquisa favorece autores e a sociedade, pois 
permite que resultados de estudos inovadores possam atingir mais velozmente seu público. Adicionalmente, a publicação continuada pode subsidiar os órgãos de financiamento e regulatórios acerca dos benefícios das pesquisas para a sociedade, sendo esse um dos critérios importantes para a concessão de financiamento (CROSSETTI; GÓES, 2018).

O tempo de publicação, em função do grande volume de submissões recebidas pela revista, também é o argumento usado pelo Portal de Revistas da Unicamp. A publicação continuada é uma forma de dar visibilidade e ampliar o acesso aos artigos já arbitrados e editorados (RODRIGUES; SANTOS, 2019).

A credibilidade conquistada pela SciELO em todo o território nacional encoraja os editores a seguir rigorosamente as sugestões. No entanto, é preciso refletir sobre a situação de cada revista e ponderar algumas desvantagens da publicação continuada.

A publicação individual dos artigos exige um planejamento prévio do editor sobre os temas, quantidade de artigos a serem publicados por ano e a distribuição geográfica e institucional dos autores - este, aliás, um dos requisitos para as revistas da coleção SciELO. Na modalidade de publicação continuada o editor não controla a quantidade de artigos publicados por autores de determinada universidade, região ou país - só vai saber ao final do ano, quando fechar o volume. Ao longo do ano a revista pode publicar grande parte dos artigos sobre um tema específico, o que também só será percebido no fechamento do volume.

A grande vantagem relacionada à publicação continuada é a velocidade, ou seja, a diminuição do tempo entre aceite e publicação dos manuscritos. Outra modalidade de publicação atende esta demanda, é a publicação antecipada, também conhecida como ahead of print (AOP), online first ou early section. Como bem comentam Packer e colaboradores (2016), os termos são usados desconsiderando a versão em papel, indicando a publicação do artigo antes da sua inserção em um fascículo regular. Trata-se e uma publicação provisória sem identificação de número e volume seguida da publicação definitiva, algum tempo depois, com os ajustes de composição e paginação no momento da inserção do artigo no fascículo e volume correspondente. 
Packer e colaboradores (2016) argumentam que na publicação antecipada ocorrem duas publicações do mesmo artigo. Esta modalidade é usada por boa parte dos periódicos de referência internacional. A publicação contínua evita a duplicidade pois o artigo possui todas as informações de composição de fascículo, não possui paginação convencional e sim um identificador eletrônico (e-location id) (SCIELO, 2018).

Uma consulta aleatória aos documentos SciELO de diferentes países permite observar que a modalidade de publicação continuada é fortemente disseminada pelo SciELO no contexto brasileiro (SCIELO, 2017a) e cubano (SCIELO, 2019). Já os critérios de Portugal (SCIELO, 2017b), Espanha (SCIELO, 2017c), Peru (SCIELO, 2015) e Costa Rica (SCIELO, 2016) são menos rígidos quanto a este requisito. Porque o requisito que favorece a velocidade de comunicação é priorizado em alguns países? Uma hipótese, que carece de mais evidências, é que em tais países a pontualidade de publicação já é atendida, e, portanto, não precisaria do recurso da publicação continuada.

\section{Referências}

CROSSETTI, M.G.O.; GÓES, M.G.O. Revista Gaúcha de Enfermagem e a publicação continuada: adaptando-se às necessidades da comunidade científica [Editorial]. Revista Gaúcha de Enfermagem, v. 39, e82653, 2018. Acesso em: 16 out. 2019.

PACKER, A., et al. Acelerando a comunicação das pesquisas: as ações do SciELO. SciELO em Perspectiva, 2016. Disponível em:

https://blog.scielo.org/blog/2016/03/10/acelerando-a-comunicacao-daspesquisas-as-acoes-do-scielo/. Acesso em: 16 out. 2019.

RODRIGUES, Camila Martins; SANTOS, Gildenir Carolino. A importância e o impacto da Publicação Contínua (PC) nos Periódicos Eletrônicos. Blog PPEC, Campinas, v.1, n.1, jan. 2019. Disponível

em: http://periodicos.sbu.unicamp.br/blog/index.php/2019/01/15/pc/. Acesso em: 16 out. 2019.

SCIELO. Guia para publicação continuada de artigos em periódicos indexados no SciELO. São Paulo; 2018. Disponível em: http://www.scielo.org/local/ Image/guiarpass.pdf. Acesso em: 2 nov. 2019. 
SCIELO. Critérios, política e procedimentos para a admissão e a permanência de periódicos científicos na Coleção SciELO Brasil. 2014. Disponível em: http://www.scielo.br/avaliacao/20141003NovosCriterios_SciELO_Brasil.pdf. Acesso em: 2 nov. 2019.

SCIELO. Critérios, política e procedimentos para a admissão e a permanência de periódicos científicos na Coleção SciELO Brasil. 2017a. Disponível em: http://www.scielo.br/avaliacao/20141003NovosCriterios_SciELO_Brasil.pdf. Acesso em: 2 nov. 2019.

SCIELO. Criterios, política y procedimientos para la admisión y la permanencia de revistas científicas en la Colección SciELO Cuba. 2019. Disponível em: http://scielo.sld.cu/pdf/criterios_2019.pdf. Acesso em: 2 nov. 2019.

SCIELO. Critérios SciELO Portugal: critérios, política e procedimentos para a admissão e a permanência de periódicos científicos na coleção SciELO Portugal. 2017b. Disponível em: http://www.scielo.mec.pt/avaliacao/avaliacao_pt.htm. Acesso em: 2 nov. 2019.

SCIELO. Criterios SciELO España: política y procedimientos para la admisión y permanencia de revistas científicas en la colección SciELO España (versión de julio de 2017). 2017c. Disponível em:

http://scielo.isciii.es/avaliacao/criterios_scielo.htm. Acesso em: 2 nov. 2019.

SCIELO. Criterios SciELO-Costa Rica. 2016. Disponível em:

https://www.scielo.sa.cr/avaliacao/avaliacao_es.htm. Acesso em: 2 nov. 2019.

SCIELO. Criterios SciELO Perú: política y procedimientos para la admisión y permanencia de revistas científicas en la colección. 2015. Disponível em: https://www.scielo.sa.cr/avaliacao/avaliacao_es.htm. Acesso em: 2 nov. 2019.

SILVEIRA, Lúcia da.; SPUDEIT, Daniela Fernanda Assis de Oliveira. Portais de periódicos: checklist para verificação de elementos de gestão. In: Encontro Nacional de Pesquisa em Ciência da Informação, 17, 2016, Salvador. Anais [...] Salvador, 2016. Disponível em:

http://www.brapci.inf.br/index.php/article/download/50145. Acesso em: 2 dez. 2019

VANZ, Samile Andrea de Souza; SILVA FILHO, Rubens da Costa. O protagonismo das revistas na comunicação científica. In: CARNEIRO, Felipe Ferreira Barros; FERREIRA NETO, Amarílio; SANTOS, Wagner dos. A comunicação científica em periódicos. Curitiba: Appris, 2019. p.19-44. 